\title{
LA IMPARCIALIDAD DEL DICTAMEN PERICIAL COMO ELEMENTO DEL DEBIDO PROCESO
}

\author{
FAIRNESS OF THE EXPERT OPINION AS AN ELEMENT OF DUE \\ PROCESS
}

\section{MAIte AgUirREZABAL GRÜNSTEIN ${ }^{1}$}

RESUMEN: El presente comentario tiene por objeto revisar la figura del perito y la objetividad e imparcialidad que deben regir los dictámenes que emita, con la finalidad de colaborar con el órgano jurisdiccional en la búsqueda de la verdad acerca de los hechos.

Palabras clave: perito, testigo, imparcialidad.

ABSTRACT: The present comment aims to review the figure of the expert and the objectivity and fairness that should govern the opinions issued in order to assist the court in seeking the truth about the facts.

Key words: expert, witness, impartiality.

\section{INTRODUCCIÓN}

En el presente comentario se analiza cómo un acuerdo de honorarios celebrado entre el perito y una de las partes puede afectar de modo manifiesto la objetividad, y consecuentemente la imparcialidad del profesional, al momento de emitir el correspondiente dictamen.

La teoría general de la prueba se inserta como un elemento integrante de la tutela judicial y del debido proceso, por lo cual se explica que hoy haya despertado el interés de los juristas desde una óptica constitucional.

Los medios de prueba pueden ser definidos como "cualquier elemento usado para establecer la verdad acerca de los hechos de la causa"2, de un modo instrumental, lo que significa que la controversia se produce respecto de ciertos hechos, y lo que debe establecerse en la sentencia es la verdad acerca de esos hechos disputados.

Es decir, que en la indagación de los hechos controvertidos, la prueba es un aspecto esencial de la función jurisdiccional, ya se trate de un procedimiento ordinario civil, penal o dentro del proceso arbitral.

\footnotetext{
${ }^{1}$ Licenciada en Ciencias Jurídicas y Sociales por la Universidad de Valparaíso, Abogada, Máster en Derecho de la Empresa por la Universidad de los Andes, Doctora en Derecho por la Universidad de Navarra. Profesora de Derecho Procesal de la Universidad de los Andes. Mail:maguirrezabal@uandes.cl

2 TARUfFo (2008), p. 15.
} 


\section{EL PERITO COMO TESTIGO EXPERTO O COMO AUXILIAR DE LA ADMINISTRACIÓN DE JUSTICIA}

Se denomina perito a un profesional o técnico, conocedor a profundidad de un tema y con capacidad de análisis, que pueda servir a un tribunal para establecer una verdad, ya sea por medio de la experiencia o de pruebas técnicas, que determinan un hecho.

En los sistemas anglosajones, el perito es un testigo que tiene la categoría de experto en áreas científicas o técnicas. Cada parte puede presentar testigos expertos, a los que preparan y además les pagan, lo que en palabras de Taruffo genera "la figura del perito o testigo como un pistolero a sueldo, dispuesto a servir a la parte que lo convoca" 3 .

En los sistemas continentales, a diferencia de lo que sucede en los del Common Law, el testigo es una figura claramente diferenciada del perito. En este sentido, este último es una persona experta en un tema que informa acerca de una determinada cuestión técnica o científica, mientras que el testigo es un tercero ajeno a los hechos controvertidos que declara sobre los mismos porque los conoce de una u otra forma y de modo personal.

Carnelutti hacía alusión a la importancia que revestía el hecho de distinguirlos estableciendo que el testigo solo relata, refiere, narra hechos; en tanto que el perito expresa juicios debido a algún conocimiento propio de su profesión y que el juzgador desconoce, considerando además que "el perito es un sujeto, el testigo es un objeto del proceso; el uno y el otro proporcionan al juez noticias, pero el origen de estas es diverso: la ciencia del perito se forma en el proceso, y la ciencia del testigo fuera del proceso, en el sentido de que el primero actúa para lograrla en cumplimiento de un encargo del juez y el segundo sin encargo alguno ${ }^{4}$.

Como bien señala Taruffo, "el perito también puede expresar sus opiniones y evaluaciones de hechos específicos, o tomar conocimiento personal de algunos hechos o determinar, además, algunos hechos relevantes" ${ }^{5}$, pero agrega que lo más importante es que el perito debe ser neutral, puesto que como colaborador de la justicia, debe entregar al órgano jurisdiccional una ayuda especializada en forma objetiva, imparcial e independiente ${ }^{6}$.

Hoy todavía se discute cuál debe ser la consideración jurídica del perito en el marco del proceso, posición que varía según los distintos ordenamientos jurídicos.

Las posturas han oscilado entre su consideración como auxiliar de la administración de justicia, o bien como un técnico que informa en el proceso a petición de la parte

\footnotetext{
${ }^{3}$ Cfr. TARUfFo (2008) p. 90. Lo descrito se produce en los EE.UU. y claramente acarrea problemas graves en materia de imparcialidad. Por lo anterior, en sistemas como el inglés, la prueba pericial solo procede previa autorización del juez, quien posee amplios controles sobre la misma, pudiendo incluso designar "un perito único conjunto para casos menos complejos.

${ }^{4}$ Carnelutti, citado por Pallares (2008), p. 565.

5 TARUFFo (2008) p. 93

${ }^{6}$ Cfr. TARUfFo (2008) p. 93. Agrega el autor que corresponde al tribunal la elección de un experto, y que además debe existir una normativa que permita garantizar la neutralidad y fiabilidad del perito.
} 
que solicita sus servicios, para dictaminar sobre cuestiones de carácter técnico que atañen a los hechos controvertidos.

Del fallo que se comenta, y sin perjuicio de lo dispuesto por los artículos $350 \mathrm{y}$ siguientes del Código Orgánico de Tribunales, en que los peritos no han sido incluidos como auxiliares de la administración de justicia, no cabe duda alguna que nos encontramos frente a un colaborador del sistema judicial, especialmente cuando el perito es designado por el propio tribunal 7 , y que es una cualidad que el testigo no detenta.

En consecuencia se puede decir que el perito, en el marco de la administración de justicia, es más un auxiliar que un asesor, porque el juez lo requiere en un determinado momento del proceso judicial constituyéndose en la persona clave para ilustrar y ayudar a esclarecer la controversia.

El perito por lo tanto, y según lo declara el fallo que se comenta, es un auxiliar de la administración de justicia, que actuando en la etapa de prueba, a través de la pericia, contribuye a mejorar el entendimiento que sobre los hechos controvertidos debe allegar el órgano jurisdiccional.

Y la forma en la que el perito debe cumplir este deber de colaboración es actuando con objetividad en la emisión del dictamen pericial que se aporta al proceso. De ahí entonces que la objetividad del dictamen constituye precisamente el mecanismo de control de la imparcialidad de la prueba pericial.

\section{LA OBJETIVIDAD E IMPARCIALIDAD DEL INFORME PERICIAL COMO GARANTÍA DE UN DEBIDO PROCESO.}

La imparcialidad es un elemento esencial del debido proceso, que afecta la actitud del juez con las partes, incidiendo específicamente en la forma como ejerce el juez su actividad en los casos concretos que se le someten a su conocimiento.

A través de la garantía de la imparcialidad, se busca que no se desdibujen en el ánimo del juez su carácter de tercero, evitando que concurra a resolver un asunto si existe la mera sospecha de que, por determinadas circunstancias, favorecerá a una de las partes, dejándose llevar por sus vínculos de parentesco, amistad, enemistad, interés en el objeto del proceso o estrechez en el trato con uno de los justiciables, sus representantes o sus abogados.

De lo que se trata, en explicación de Montero Aroca, es evitar en la declaración del Derecho Objetivo todo designio anticipado o la prevención para no cumplir con rectitud la función jurisdiccional ${ }^{8}$.

\footnotetext{
7 Criterio que se ve reforzado con la reforma introducida por la Ley 20.192, de 26 de junio de 2007, que modifica el artículo 416 del Código de Procedimiento Civil, estableciendo que "Cuando el nombramiento se haga por el tribunal, lo hará de entre los peritos de la especialidad requerida que figuren en las listas a que se refiere el artículo siguiente y la designación se pondrá en conocimiento de las partes para que dentro de tercero día deduzcan oposición, si tienen alguna incapacidad legal que reclamar contra el nombrado. Vencido este plazo sin que se formule oposición, se entenderá aceptado el nombramiento".

${ }^{8}$ Cfr. Montero (1999) p. 332.
} 
La imparcialidad no debe ser confundida con la independencia, ya que esta última se refiere a una cuestión previa, de organización, a través de la cual se pretende liberar al juez de toda subordinación que no sea la que el juez deba estrictamente al Derecho.

La imparcialidad "no es una característica abstracta de los jueces y magistrados, sino que hace referencia concreta a cada caso que se somete a su decisión. Por ello la ley tiene que establecer una lista cerrada de situaciones objetivas que conviertan a los jueces en sospechosos. La mera concurrencia de una de estas situaciones (...) obliga al juez a abstenerse y permite a la parte recusarlo..." .

La exigencia de un actuar imparcial se hace extensiva a todo aquel que de una u otra forma, intervenga en el proceso, es decir, la regla se hace extensiva a los testigos, a los peritos, etc., quienes se verán afectados por causales de inhabilidad en el evento que dicho requisito falte.

Se ha señalado por la doctrina que el peritaje es una actividad realizada por "personas especialmente calificadas, distintas e independientes de las partes y del juez del proceso, por sus conocimientos técnicos, artísticos o científicos, mediante el cual se suministra al juez argumentos o razones para la formación de su convencimiento respecto de ciertos hechos cuya percepción o entendimiento escapa a las del común de las gentes. Es una prueba ilustrativa sobre alguna materia técnica, que escapa al conocimiento del magistrado" ${ }^{10}$.

Es que por perito debemos entender aquel tercero, técnicamente idóneo y capaz, llamado a dar opinión y dictamen fundado en un proceso, acerca de la comprobación de hechos cuyo esclarecimiento requiere conocimientos especiales sobre determinada actividad, técnica o arte, el cual es ajeno al juzgador.

La finalidad de esta prueba, como la del resto de las previstas en la ley, consiste en acreditar los hechos que fundamentan las pretensiones de las partes en el proceso, con la particularidad, de que el objeto de la prueba pericial son hechos que no son del común saber de las partes o del juez, de modo que el perito, mediante su dictamen pericial, proporciona al tribunal los conocimientos técnicos necesarios para la valoración de los hechos objeto de la controversia.

Es decir, cuando el perito actúa conforme con los criterios válidos y vigentes en la disciplina que se trate y los aporta al tribunal diciendo la verdad, se garantiza el mínimo necesario de imparcialidad científica, objetiva, que debe concurrir en el trabajo de examen y emisión del dictamen pericial.

Nuestra jurisprudencia ha ratificado este criterio señalando que "de acuerdo a lo establecido en los artículos $411 \mathrm{~N}^{\mathrm{os}} 1^{\circ}, 13$ No 2, 414, 419 y 421 del Código de Procedimiento Civil, es de la esencia que la prueba de peritos que en "la ilustración de las cuestiones que debe resolver el Juez, el perito, se refiera y deba ceñirse necesariamente a la "apreciación" de "puntos de hecho" y de aquellas "circunstancias" pertinentes en que se necesiten "conocimientos especiales de una ciencia o arte", siendo precisamente por ello que en la designación de todo perito habrá de estarse al "título profesional" que tuviere o, en su defecto y en su caso, a la "calidad" o "aptitudes" que "deben tener" los

\footnotetext{
9 NÚNEEZ (1998), p. 4.

${ }^{10}$ FALCÓN (2003) p. 4.
} 
referidos peritos en relación al "punto o puntos materia del informe", agregando que "carecerá de valor en su dictamen todo aquello que escape a la "ciencia o arte" que el perito profese, siendo consiguientemente también ajeno a su natural órbita de competencia todo juicio de valor y con mayor razón toda calificación jurídica que saliéndose de ese ámbito emita el perito al cumplir su encargo" ${ }^{11}$.

En lo que respecta a las reformas procesales llevadas a cabo en nuestro país en los últimos años, y en lo que dice relación específicamente con la prueba pericial, dichas reformas o proyectos de reforma han tendido a adoptar una figura que en los países del Common Law va en retroceso, y que consiste precisamente en considerar al perito como un testigo experto, y en que la prueba pericial es casi de iniciativa exclusiva de las partes.

En estos sistemas se han criticado de modo reiterado aspectos tales como los mecanismos de nombramiento del experto, o la falta de control respecto de la suficiencia de calificación del perito. Lo anterior ha llevado a modificar las reglas procesales en la materia tanto en los Estados Unidos como en Inglaterra ${ }^{12}$.

Las nuevas legislaciones procesales que contemplan el proceso por audiencias han introducido reformas importantes en materia de prueba pericial, estableciendo más o menos mecanismos de control para que la prueba se rinda asegurando estándares de imparcialidad y objetividad.

Así, el Código Procesal Penal privilegia la elección del perito por las partes, debiendo además el experto prestar declaración en la audiencia de juicio oral. Además, en su artículo 314, exige que el informe sea emitido con imparcialidad, estableciendo un control de admisibilidad en que el juez de garantía debe verificar que el perito otorgue suficiente garantía de seriedad y profesionalismo ${ }^{13}$.

Establece también el artículo 318 del Código Procesal Penal que los peritos no podrán ser inhabilitados, pero, agregando en el artículo 317 una importante limitación, esto es, que no podrán ser peritos aquellos que no pueden declarar como testigos en el juicio.

En lo que respecta al procedimiento laboral y al de familia, han contemplado la regulación de la prueba pericial en términos similares, estableciendo el primero que cuando se rinda prueba pericial, el informe deberá encontrarse a disposición de las partes con anterioridad a la audiencia de juicio, y que el juez podrá eximir al perito de concurrir a declarar a esa audiencia, admitiendo el informe como prueba ${ }^{14}$.

${ }^{11}$ Considerando segundo del fallo de fecha 4 de agosto de 1998, pronunciado por la Corte de Apelaciones de Santiago en causa caratulada "Arcaya y López S.A con Tecnología del Aluminio Ltda".

${ }^{12}$ Cfr. en este sentido, TARUfFo (2008) pp. 92-93. En el caso de los Estados Unidos, durante el año 2000 se modificó la regla 702 de las Federal Rules of Evidence, estableciendo estándares para la admisibilidad de las pruebas científicas, entre las que destaca por ejemplo el control sobre la fiabilidad del método utilizado por el perito. En Inglaterra se ha producido una situación parecida, en donde se exige como obligación fundamental del perito la de "proceder con verdad, imparcialidad y transparencia ante el tribunal".

${ }^{13}$ Artículo 316 del Código Procesal Penal.

${ }^{14}$ Artículo 453 del Código del Trabajo. La facultad que posee el juez para eximir al perito de concurrir a prestar declaración debe ser adoptada con el acuerdo de las partes. De no ser así, impediría a nuestro juicio que las partes puedan efectuar observaciones respecto de la persona del perito o de la veracidad del informe o de su declaración, infringiendo con ello su derecho de defensa. 
En el caso del procedimiento seguido ante los tribunales de familia, los artículos 45 y siguientes de la Ley 19.968 repiten el sistema adoptado por el Código Procesal Penal, estableciendo un riguroso control de la prueba pericial, a través de exigencias para las partes, como las de acompañar antecedentes que acrediten la idoneidad del perito ${ }^{15} \mathrm{o}$ la etapa previa de admisibilidad de la prueba pericial efectuada por el juez ${ }^{16}$.

En la actualidad, la forma como nuestra legislación procesal civil protege la imparcialidad de la prueba pericial, es haciendo aplicable al perito las normas sobre inhabilidades de los testigos. Así, señala el artículo 417 del Código de Procedimiento Civil que "el perito que acepte el cargo, deberá declararlo así, jurando desempeñarlo con fidelidad”, mientras que el artículo 413 del citado cuerpo legal, dispone expresamente en su numeral $1^{\circ}$, que no podrán ser peritos aquellos que sean inhábiles para declarar como testigos en el juicio.

A su vez, el artículo 358 N 6 del Código de Procedimiento Civil establece que son inhábiles para declarar como testigos, "los que a juicio del tribunal carezcan de la imparcialidad necesaria para declarar por tener en el pleito interés directo o indirecto", entendiendo la jurisprudencia, de modo reiterado, que este interés debe ser de carácter patrimonial, lo que en el caso concreto que se comenta, ocurriría.

Sin embargo, el proyecto de ley que busca aprobar un nuevo Código Procesal Civil ${ }^{17}$ no ha tomado en cuenta estos criterios más conservadores al momento de regular la prueba pericial.

El artículo 289 del Proyecto en su actual redacción, dispone que "Las partes podrán recabar informes elaborados por peritos de su confianza y solicitar que estos sean citados a declarar a la audiencia de juicio, acompañando los antecedentes que acreditaren la idoneidad técnica del perito y su eventual relación con las partes del juicio y del tribunal", agregando que "procederá la prueba pericial en los casos determinados por la ley y siempre que, para apreciar algún hecho o circunstancia relevante para la causa, fueren necesarios o convenientes conocimientos especiales de una ciencia, arte u oficio"18.

Agrega además el artículo 291, que los honorarios y gastos del perito corresponderán a la parte que lo presente, disponiendo el artículo 292 que estos no podrán ser inhabilitados, sin perjuicio de poder dirigírseles en la audiencia de juicio preguntas orientadas a determinar su relación con las partes o el tribunal ${ }^{19}$.

\footnotetext{
15 Artículo 45 de la Ley 19.968.

${ }^{16}$ En este sentido, dispone el artículo 47 de la Ley 19.968 que "El juez admitirá la prueba pericial cuando, además de los requisitos generales para la admisibilidad de las solicitudes de prueba, considerare que los peritos otorgan suficientes garantías de seriedad y profesionalismo. Con todo, el tribunal podrá limitar el número de peritos, cuando resultaren excesivos o pudieren entorpecer la realización del juicio".

${ }_{17}$ Mensaje $\mathrm{N}^{\circ}$ 398-357, de fecha 19 de mayo de 2009.

18 Tendencia opuesta a la que actualmente se sigue en el sistema anglosajón, en que la procedencia de la prueba pericial, en que el juez ejerce un control importante sobre la admisibilidad y forma de rendirla.

19 Creemos que en definitiva, el proyecto dejaría de lado el sistema de inhabilidades que actualmente regulan la prueba pericial, y la reforma introducida por la Ley 20.192, de 26 de junio de 2007, que modifica el artículo 416 del Código de Procedimiento Civil, estableciendo que "Cuando el nombramiento se haga por el tribunal, lo hará de entre los peritos de la especialidad requerida que figuren en las listas a que se refiere el artículo siguiente y la designación se pondrá en conocimiento de las partes para que dentro de tercero día deduzcan oposición, si tienen alguna incapacidad legal que reclamar contra el nombrado. Vencido este plazo sin que se formule oposición, se entenderá aceptado el nombramiento”.
} 
Como podemos observar, el proyecto de reforma procesal civil adopta la misma estructura que a propósito de la prueba pericial contempla el Código Procesal Penal, pero con la salvedad de que este último resulta más riguroso que el proyecto de legislación procesal civil, en cuanto al control de la objetividad e imparcialidad de la prueba pericial, puesto que en el ámbito procesal civil no se ha previsto un control de admisibilidad de la prueba pericial por parte del juez con el objeto de garantizar su seriedad, ni tampoco la posibilidad de inhabilitar a los peritos que no puedan declarar como testigos.

\section{LA DECISIÓN DE LA CORTE DE APELACIONES}

En la causa sobre constitución de servidumbre minera caratulada "Angloamerican Sur S.A. con Constructora Daves Limitada”, Rol No 33.117-2008, seguida ante el 24º Juzgado Civil de Santiago, la parte demandante recurre de apelación la sentencia definitiva, recurso que rola con el No 2166-2010.

En primera instancia se ordenó una prueba pericial, y el informe solicitado en la materia, concluyó que la afección patrimonial de la demandada, producida por la constitución de la servidumbre en el inmueble ascendía a una muy importante cantidad de dinero.

La sentencia definitiva de primera instancia condenó a la demandante al pago de la indemnización ascendente a la suma indicada por el perito en su dictamen.

Con fecha 11 de diciembre de 2009, ante el juez de primera instancia que conoció del litigio, el perito judicial designado promovió un cobro incidental de honorarios que hizo pública la existencia de un contrato de honorarios cuya cuantía se estipuló a las resultas pecuniarias del juicio, según el siguiente detalle: "CUARTO: Ante el evento que a la empresa Constructora le sea favorable la demanda, por sobre $\$ 250.000 .000$.- (doscientos cincuenta millones), pagará la suma de $\$ 10.000 .000$ extra, hasta completar los $\$ 15.000 .000$ (quince millones) como suma total y sin impuestos. Ellos serán pagados a más tardar 5 días posterior a la resolución del Tribunal”.

La Corte de Apelaciones de Santiago, con fecha 10 de marzo de 2011, conociendo del recurso de apelación interpuesto por la demandante, confirma el fallo de primera instancia pero con declaración de que el monto de la indemnización que deberá pagarse al demandante es significativamente menor a la ordenada pagar por el fallo recurrido.

La decisión se funda en el hecho de que la existencia del contrato de honorarios acompañado por el perito con ocasión del cobro incidental de los mismos, afecta de modo manifiesto su imparcialidad, por cuanto, y respecto del informe, "el propio perito ha reconocido que al momento de su confección tenía un interés patrimonial en la resulta de este juicio, elemento que le hace perder la imparcialidad que debe tener al momento de ejecutar la labor que le encomendara el tribunal, sobre todo si se tiene presente que su labor es de auxiliar en la administración de justicia”.

Por lo anterior, la Corte de Apelaciones resta cualquier mérito probatorio al informe pericial, y fija la indemnización de perjuicios correspondiente en consideración a las características del inmueble, la superficie total afectada con la constitución de la servidumbre, el total del inmueble, a su destino, y a si se pueden o no desarrollar actividades económicas en este. 


\section{CONCLUSIÓN}

El fallo en comento tiene el mérito de haber restado mérito probatorio al dictamen pericial, por cuanto considera que el contrato de honorarios celebrado entre el perito y la parte demandada afecta de modo indiscutible la imparcialidad y buena procesal con que debe llevarse a cabo un informe pericial.

Ello porque el establecer premios según sea el resultado del dictamen, necesariamente implica que el perito se aleje de los criterios de objetividad que gobiernan su disciplina.

De lo señalado puede concluirse que nos encontramos ante una situación manifiesta de falta de imparcialidad por parte del perito, conducta que atenta también contra la buena fe procesal ${ }^{20}$ y contra la función del experto como auxiliar o colaborador de la administración de justicia.

El informe del perito debe, entonces, lograr que el juez llegue a una propia convicción, sea de acuerdo con el mismo o apartándose, y para ello es necesario que el experto se valga de todos los medios posibles para fundamentar su cometido a través de sus saberes profesionales y sana crítica, no olvidándose que es un auxiliar de la justicia y debe mantener siempre los estándares de objetividad requeridos.

\section{BiBLiografía CitAdA}

FalCón, E., Tratado de la prueba, t. 2, Astrea, Buenos Aires, 2003, 2.696 pp.

LozAnO-Higuero, M., "La probidad en el nuevo proceso civil (Respecto a las reglas de la buena fe procesal. Multas por su incumplimiento)", en Revista Vasca de Derecho Procesal y Arbitraje, tomo XIV, 2002, pp. 29-47.

Montero ArocA, J., Sobre la Imparcialidad del Juez y la incompatibilidad de funciones procesales, Tirant lo Blanch, Valencia, 1999, $334 \mathrm{pp}$.

NúÑEZ OJEDA, R., "La imparcialidad objetiva del juzgador penal y el principio acusatorio (el caso español)", en RDJ, t. XCV, N 1, 1998, pp. 1-36.

Pallares E., Diccionario de Derecho Procesal Civil, Porrúa, México, 2008, 847 pp. PiCÓ I JunOY, J., El principio de la buena fe procesal, Bosch, Barcelona, 2003, 395 pp. TARuffo, M., La prueba, Marcial Pons, Madrid, 2008, 324 pp.

20 PICÓ I JUNOY (2003) p. 69, la ha definido como "aquella conducta exigible a toda persona, en el marco de un proceso, por ser socialmente admitida como correcta”, mientras que LOZANO-HIGUERO (2002) p. 326, ha señalado que por el principio de probidad debe entenderse aquel "conjunto de reglas, standards o criterios de conducta, de carácter ético, social y deontológico, a que deben adaptar su comportamiento los sujetos procesales (partes, profesionales causídicos, juez, secretario, personal auxiliar y secretarial, peritos, testigos, etc.) en el curso del proceso y todo acto procesalmente relevante". 